\title{
MANAGING CONTRACTUAL RELATIONSHIPS IN VIRTUAL ORGANIZATIONS WITH ELECTRONIC CONTRACTING
}

\author{
Daniel Burgwinkel \\ University of St. Gallen, Institute for Media and Communications Management \\ SWITZERLAND \\ daniel.burgwinkel@unisg.ch
}

\begin{abstract}
For virtual organisations the efficient negotiation and management of contracts is essential. The reduction of the time-to-contract and risk minimisation in a contractual agreement is one prerequisite for establishing flexible and spontaneous business relationships over the Internet.

The aim of this paper is to explore new possibilities for managing contractual relationships with the help of the emerging technology of electronic contracting. With the adoption of XML as format for electronic contracts and introduction of negotiation tools, new opportunities for the support of the contract management for virtual organisations arise. This paper examines different types of electronic contracts and their potential use in virtual enterprises.
\end{abstract}

\section{INTRODUCTION}

The negotiation and management of contracts in virtual organisations is a challenging task from the legal as well as from the business point of view. The internal contractual agreements between the participants of a virtual enterprise as well as the relation to the customer have to be defined. Moreover, the dependencies between these internal and external rights and obligations must be synchronised.

This paper discusses how electronic contracts and contract management tools can support virtual enterprises. The basic forms of electronic contracts are examined. Then the functionality of electronic contracting applications is evaluated. And finally, a scenario of a virtual application service provider demonstrates how contract management tools can be applied in a virtual enterprise.

\section{ELECTRONIC SIGNATURES AND CONTRACTS}

Legal regulations, namely the European directive for electronic signatures (EU, 1999) and national e-commerce regulations, have set up a framework for using electronic contracts in business. Electronic contracts are contractual agreements, 
represented as digital information and signed with the digital signatures of the parties. According to the new regulations a text that is signed with a digital signature has the same conclusiveness as a hand-written signature.

The terms contract management and electronic contracting describe applications, which support the formation and management of contracts. Electronic contracting focuses on digital contracts and internet-based collaboration, whereas contract management covers applications that manage paper-based documents, contract data and electronic documents. Electronic contracting focuses on negotiation of the terms and conditions of the contract as well as the monitoring of contract performance (Lee, 1998). The term electronic contracting system describes applications that support the formation and negotiation of electronic contracts. These systems may also contain decision support functions.

The potential of electronic contracting has been discussed since the research in electronic marketplaces began. A overview of current research initiatives in econtracting is given in (Angelov \& Grefen, 2001).

Besides the introduction of digital signatures and contract management applications, the development of XML-technologies and industry specific XML vocabularies is important for further progress in e-contracting. XML can be used for representing contracts in a semi-structured format.

Currently, several EU-projects are working on the introduction of electronic contracting tools in specific industries. The project OCTANE (Künne, 2001) is developing a platform for the construction industry. In the scenario developed by this project several small construction companies form a virtual enterprise to perform as general contractor for a large construction project. The E-NTRY project (Coscia \& Nicolodi, 2000) is developing a web-based e-commerce platform to support tendering, bidding and contract negotiation.

\section{TYPOLOGY OF ELECTRONIC CONTRACTS}

An electronic contract is defined as a legally binding agreement in a digital form, that is signed with the electronic signatures of the parties. With the introduction of electronic signatures different forms of electronic contracts will emerge. They can be differentiated by their form and by the process of the contract formation. Three forms of electronic contracts are analysed below.

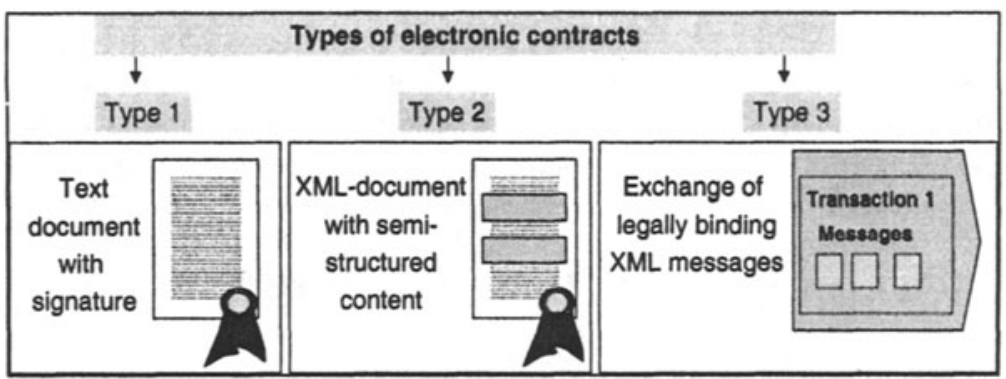

Figure 1 - Types of electronic contracts 


\subsection{Text document with digital signatures}

According to the new legal regulations for digital signatures an electronic document with a digital signature has the same legal status as a hand-written contract. The basic form of e-contracts are electronic text documents, e.g. an e-mail message, signed with the signatures of the parties.

For the creation of the document a word processor or a joint editing applications can be used. This basic type of contract contains only text and layout information. Software vendors like Adobe offer applications that allow to sign PDF files (Portable Document Format) with electronic signatures.

In comparison to paper-based contracts electronic documents can be processed more efficiently. For virtual enterprises the deployment of CSCW (Computersupported-collaborative-work), e.g. joint edition over the internet, can be used to enhance the collaboration in the contracting process.

\subsection{XML-Contract with digital signatures}

With the deployment of XML as underlying format for the contract, an additional functionality can be realised. The content of the contract can be represented in a semi-structured format, e.g. data elements and clauses can be marked-up with XMLTags (Greunz, 2000).

The development of the technical standards, namely XML-Schemas and XMLDigital Signatures, as well as the creation of industry standards are important for innovations in the field of e-contracting. On basis of XML-Schemas the elements and data types of a contract can be defined.

To understand how XML can represent the content of a contract we take a closer look at the parts of a contract. The contents of a contract can be classified in four groups (Griffel, 1999):

- Who - Information about the parties can be represented with XML. For each party the corresponding role, e.g. "buyer" or "seller", can be assigned.

- What - The product or service, which is object of the contract, can be described in XML. For the product specification industry specific XML vocabularies can be used. In addition the obligations, which the parties have to fulfil, can be described in a structured form.

- How - The information regarding the performance of the contract and the business processes can be described using XML. The process and the relation between the obligation are defined, for example the time of the product delivery. In addition the rules for non-performance are defined, e.g. which clause applies if a party does not fulfil its obligation.

- Legal - Terms and conditions of a contract can be represented in a semistructured format. In specific trade scenarios a standardised vocabulary, e.g. INCOTERMS for international trade, can be used. Moreover efforts are being made to use XML in the legal practice, namely the Legal XML initiative (LegalXML, 2001).

The use of XML as a format for contracts will bring several benefits. Firstly, these XML-based contracts are machine-processable. The contract can be imported into contract management and negotiation tools. In this way the XML-document can be 
analysed by decision support systems. For example, the frequency of a clause in different contracts can be evaluated.

Secondly, the use of industry specific XML vocabularies can lead to a better specification of the contract, e.g. the use of XML for a product description. The principle of XML-Schema can be used to design contract templates. A contract template defines the document structure of the contract and has predefined clauses and legal terms.

\subsection{Exchange of legally binding XML-messages}

In the previous described contract types all information is represented in one document. In contrast to type 1 and 2 a contractual agreement can also be represented by a stream of legally binding messages in an electronic network.

One well-known example of the use of legally binding electronic messages is EDI. With the introduction of EDI we have seen the movement towards a paperless transmission of commercial data. Whereas EDI is used by trading partners who already know each other, the challenge of the next years is to establish open electronic trading environments (Mitrakas, 1997). Currently the ebXML initiative (ebXML, 2001), a successor of Open EDI, is developing a e-commerce framework that will enable a global open trading environment.

\section{FUNCTIONALITY OF E-CONTRACTING SYSTEMS}

In the following paragraphs we want to examine categories of electronic contracting systems, that can be deployed in virtual enterprises. Tan has made a classification of the functionality of electronic contracting systems (Tan, 2001). From his model we want to examine the categories legal background information, contract preparation and decision support and their impact on virtual enterprises.

There are initiatives that provide legal background information on web sites. Information about laws and regulations and recommendations support the parties in the formation of a contract. There are several EU-projects, e.g. eLEGAL (eLEGAL, 2001)and ECLIP (ECLIP, 2001), that support small and medium-size enterprises with legal information about e-commerce. In addition to the information model contracts are provided.

The category of contract preparation tools includes functions of contract drafting and version management. Commercial tools, such as Dicarta (Dicarta, 2001), as well as research projects, e.g. the Memo (Schopp, 2001) project, focus on these supporting functions. For drafting a contract joint editing is provided by these tools.

Decision Support can help to manage legal as well as business decision in the contracting process. The two main functions are "What if analysis" and tools that support negotiation strategies. In a "What if analysis" a company can evaluate the consequences and the risks of a contractual agreement. For example the consequences of non-performance can be simulated. To enable the strategic planning and negotiation an aggregated business view of the contractual obligations and liabilities can be provided. Especially in multiparty contract the relation of one contract to other contract, e.g. to master agreements, is important. In extension the 
frequency of the appearance of a specific clause in different contracts of one company can be analysed.

The deployment of these categories of applications can give an effective support for the management of the contractual relations in a virtual enterprise.

\section{SCENARIO FOR E-CONTRACTING}

Having discussed the forms of electronic contracts and supporting tools for the formation and management of contracts the following section will describe a scenario for contract management in a virtual organisation.

Contract management can be deployed for the agreements within the virtual enterprise as well as in the contractual relation to the customer. The following assumptions are made:

- Each participant in the virtual enterprise will have an internal contract management to handle all his contracts.

- The virtual enterprise will deploy a contract management that manages the internal consortium contract as well as the customer contracts.

- For the negotiation with the customer a shared e-contracting tool will be applied.

- The customer will deploy its own contract management to monitor the performance of the virtual enterprise.

To illustrate the use of e-contracting tools for virtual enterprises we describe the case of virtual Application Service Provider (ASP). This virtual ASP is a network of independent companies: an internet service provider is responsible for the network access, a data processing centre operates the system, a software vendor provides the software. Following illustration describes the scenario:

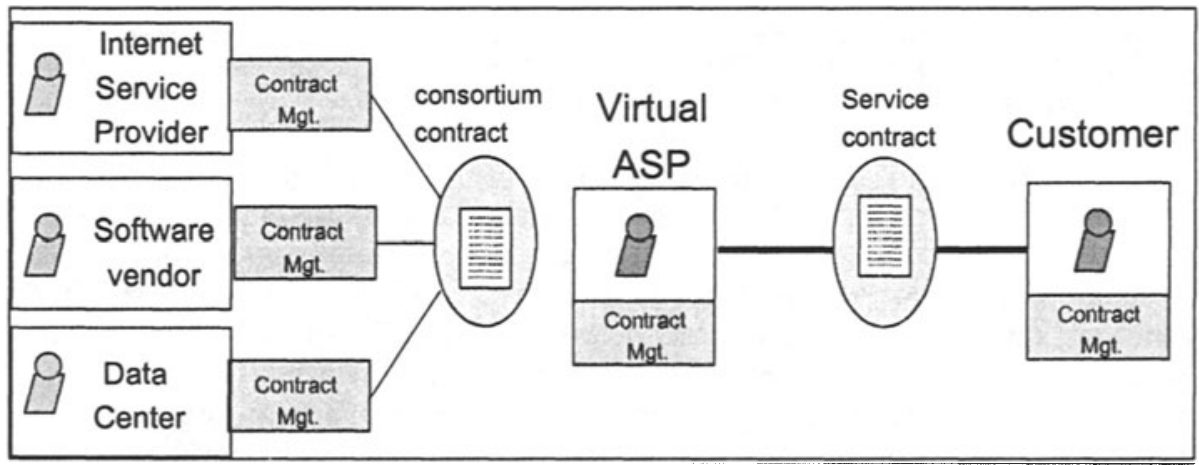

Figure 2 - Scenario of a virtual Application Service Provider (ASP)

The three companies agree to offer a joint service: for a monthly fee a customer can use an application over the Internet. From a legal point of view the virtual ASP acts as one company in the relation to its customers.

The participants of the ASP have to negotiate an internal contract for the service offering. For this purpose an e-contracting platform is applied. An important topic in the negotiation of IT-service is the definition of service level agreements (SLA). The 
SLA describes the service the ASP offers to the customer, e.g. the Quality of Service (QoS), and the responsibilities in case of a fault. This contractual agreement with the customer has to be represented in the contract management of the virtual ASP as well as in the systems of each partner. For the negotiation between the virtual ASP and the customer contracting tools are used. The virtual ASP will use its contract management system to store and manage the contracts.

To illustrate the capabilities of XML-contracts we assume that there is a XMLvocabulary for service level agreements.

<seller> Virtual ASP </seller> is expected <obligation 1) to provide a web service for order management </obligation 1> to <customor> Company Inc. 〈/customer >

The technical details of the web service can be described in the web service description language (WDSL, 2001). In addition the specification of the SLA can be defined with XML.

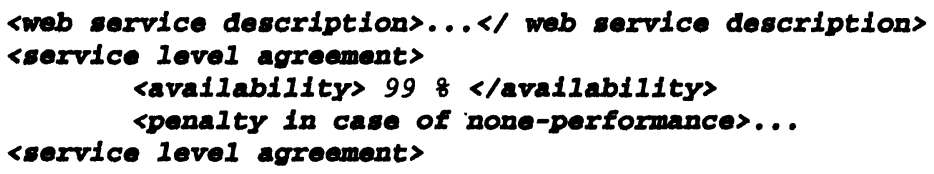

The application service provider can specify electronic contracts that represent the contractual relationships with his partners:

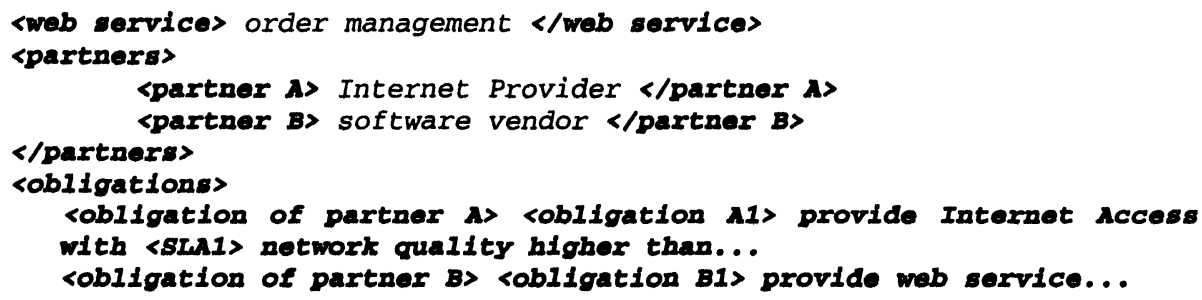

The first benefit is that the parameters of the SLA can be automatically processed in operational systems, e.g. in a trouble-ticket system. Furthermore, we assume that the structure of the clauses in the contract is represented in XML. An example is that the ASP has the obligation to respond to fault reports of the customer within 2 hours. Because the virtual ASP has full responsibility for the enduser service, this SLA has an impact on the internal relation of the ASP. In the internal contract the remedies for non-performance of one party are defined. EContracting tools can help to negotiate these multi-tiered service-level agreements and simulate the legal consequences of fault scenarios.

In addition to the benefits of an optimised operation the capability to efficiently negotiate contracts can lead to new types of service contracts. One opportunity is to enable a better customisation of the contract to the needs of the customer. Similarly, several short-term and demand driven contracts could be established instead of a long-term contract. 


\section{BENEFITS AND CONTRAINTS OF E-CONTRACTING}

\subsection{Benefits of e-contracting}

E-Contracting can provide benefits for virtual enterprises. Process automation and negotiation support can lead to more efficient collaboration. The time-to-contract can be reduced, because the efforts for negotiation, validation of legal aspects and controlling the contract performance are optimised.

Furthermore, electronic contracting systems can help to prepare contracts, that are acceptable for both partners from a legal as well as from a business perspective. Additionally, contract management provides the means for optimised risk management. Risk management is important especially for virtual enterprises. If a partner or subcontractor does not deliver the specified quality, remedies for the virtual enterprise can occur.

\subsection{Constraints of e-contracting}

Several hurdles have to be overcome to establish e-contracting as a new collaboration technology. Studies on e-mail negotiation have shown, that trading partners behave differently in electronic negotiation than they would in a face-toface meeting (Shell, 2001). The negotiation of a contract has a social dimension that should not be underestimated. The face-to-face negotiation of a contract is a well established ritual. Moreover, e-contracting affects the traditional roles and attitudes of sales and purchasing departments. The established ritual of creating a contract will not change from one day to the next. Nevertheless, there is a growing need for IT-support in contract management which will provide assistance in handling the growing complexity of contractual relationships.

Besides the constraints of communication technology other hurdles to adoption of e-contracting applications as interorganizational systems (IOS) also exist. For the acceptance of inter-firm collaboration supported by IOS three barriers have been identified by $\mathrm{Li}$ and Williams (Li \& Williams, 2001). Firstly, there are technical barriers. In the case of e-contracting all partners must have electronic signatures and use a shared platform. The second barrier is the willingness to share sensitive business information with partners and suppliers. Thirdly companies must be willing to deploy interorganizational systems and try out new types of electronic collaboration.

\section{SUMMARY}

The introduction of e-contracting technology will become an important component for conducting e-business with virtual enterprises. Negotiation and contract management can be optimised. The goal of the negotiation is to get to an agreement, which is acceptable and legally valid for all parties. The focus of the contract management is to handle all contractual relationships of the company in an optimal way.

However, the adoption of electronic signatures and XML-based contracts are the first steps towards an IT-supported contracting process. Depending on the type of 
industry, different forms of contracts will emerge. It is likely that existing marketplaces, e.g. e-procurement, will extend their services with e-contracting services.

Further research is needed on the technology side as well on the business side. It is important to perceive and recognise the business requirements and determine which support functions are needed and will be accepted by the user. For the technological development the emerging Semantic Web technologies will play a major role.

\section{REFERENCES}

1. Angelov S, Grefen P. B2B eContract Handling - A Survey of Projects, Papers and Standards. Universităt Twente, Niederlande. CTIT Technical Reports, 2001.

2. Coscia E; Nicolodi S. "The E-NTRY Web-based E-commerce Platform: an advanced infrastructure supporting Tendering, Bidding and Contract Negotiation". In: Proceedings of the E-Business and E-Work conference, Madrid , 2000.

3. Dicarta, [Internet] URL:<www.dicarta.com > [accessed November 22, 2001]

4. ebXML, [Internet] URL:<www.ebxml.org $>$ [accessed November 1, 2001]

5. ECLIP, [Internet] URL:<www.eclip.org $>$ [accessed November 22, 2001]

6.ELEGAL. [Internet] URL:<http://cic.vtt.fi/projects/elegal/public.html >[accessed November 22, 2001]

7. EU Directive 1999/93/EC of 13 December 1999 on a Community framework for electronic signatures [Internet] URL:<http://europa.eu.int/comm/internal_market/en/media/sign/Dir99-93-ecEN.pdf>.

8. Greunz M, Schopp B, Stanoevska-Slabeva, K. "Supporting Market Transactions through XML Contracting Container". In: Proceedings of the Sixth Americas Conference on Information Systems (AMCISS 2000), Long Beach, 2000.

9. Griffel F, Boger M, Weinreich H, Lamersdorf W, Merz M. "Electronic Contracting im Internet". In: Kommunikation in Verteilten Systemen (KiVS), Berlin, Heidelberg, New York: Springer-Verlag, p. 314 - 325, 1999.

10. Küne N, Jungemann-Dorner M, Lam T. "Open Contracting TransActions in the New Economy (OCTANE project)". In: Proceedings of eBusiness and eWork 2001, Amsterdam: IOS Press, 2001.

11. Lee, Ron. "Towards Open Electronic Contracting". In: EM - Electronic Markets, Vol. 8, No. 3, 1998.

12. Legal XML, [Internet] URL:< www.legalxml.org >[Accessed November 1, 2001]

13. Li F, Williams H. "Interorganizational systems to support strategic collaboration between firms" In: E-Commerce and V-business - business models for global success, ed. Stuart Barnes, Oxford: Butterworth Heinemann, 2001.

14. Mitrakas, Andreas. Open EDI and law in Europe: a regulatory framework. Haque: Kluwer Law International 1997.

15. Schoop M, Quix. C. "DOC.COM: Combining Document and Communication Management for Negotiation Support in Business-to-Business Electronic Commerce". In: Proceedings of 34th Hawaii International Conference on System Sciences (HICSS 01), 2001.

16. Shell, Richard. "Electronic Bargaining: The Perils of E-Mail and the Promise of Computer-Assisted Negotiations". In: Wharton On Making Decisions, ed. Stephen Hoch, Howard G. Kunreuther. New York: Wiley, 2001.

17. Tan Y, Thoen W, Ramanathan S. "A Survey of Electronic Contracting Related Developments". In: Proceedings of the 14th Bled Electronic Commerce Conference. Bled, Slovenia, 2001.

18. WDSL (Web service description language) [Internet] URL:< http://www.w3.org/TR/wsdl> [accessed November 22, 2001] 